\title{
Amalia Ran \\ Tierras de promisión: \\ Sión, Argentina y sus representaciones narrativas en la ficción judeoargentina
}

La recuperación de la memoria colectiva es un tema fecundo de la narrativa argentina de las últimas décadas. El cuestionamiento sobre el legado de la historia, la problemática del olvido y la necesidad de rescatar, conservar y salvar las huellas del pasado se establecen dentro de la ficción como si fueran parte de un proceso de purificación colectiva o de enseñanza de una lección. En la sociedad argentina actual, este proceso es relacionado con la necesidad de redefinir los parámetros del imaginario argentino para incluir ciertos grupos marginados hasta el momento que reclaman su derecho de articular su historia. Particularmente, después de la última dictadura militar (1976-1983) y el consecuente trauma nacional. Las nuevas condiciones socioeconómicas, políticas y culturales en Argentina de los últimos años -debido a procesos de fragmentación y privatización, al impacto de la invasión informática y de la comunicación masiva a toda parte, y a la infiltración de empresas transnacionales que cambiaron el paisaje urbano y humano- impactan también en el modo en que se desea archivar el pasado y recrear el imaginario colectivo.

Dentro de la colectividad judeoargentina, sobresale asimismo la prevalencia del debate acerca de la imagen deseada para representar a la comunidad que sufrió cambios profundos a partir de los ochenta y que debe enfrentarse con nuevos desafíos: desde la asimilación y el alejamiento de porcentajes mayores de sus miembros, ${ }^{1}$ nuevas expre-

1 Un factor importante que se relaciona con el alejamiento de las instituciones judías y la asimilación era la imposibilidad de sufragar los gastos de pertenencia a los clubes sociales, escuelas y sinagogas. Asimismo, el descenso de la matriculación en colegios judíos durante esa época se vincula con los problemas económicos en Argentina desde la hiperinflación de los ochenta, que impactó a la clase media, a la cual pertenecían muchas familias judías. Un trabajo que se realizó en 1998 en las escuelas judías determinó que más del $65 \%$ de la comunidad no estaba asociado con ninguna organización comunitaria (Chab 2001: 211). 
siones de judaísmo laico y de oportunidades religiosas alternativas hasta la revaluación de la relevancia del sionismo y de la afiliación con Israel para las nuevas generaciones judeoargentinas, cuya pérdida de valores morales y de fe ideológica es señalada a menudo como representativa de la realidad argentina y comunitaria actual. Los dos atentados terroristas contra la embajada israelí en Buenos Aires (1992) y el edificio de la Asociación Mutua Israelita Argentina (AMIA, 1994) deben ser analizados dentro de esta complejidad de desafíos recientes y antiguos en Argentina y como reflejo de la confusión que todavía prevalece en la sociedad argentina, y en general respecto a los vínculos entre la comunidad judeoargentina y el Estado de Israel. ${ }^{2}$ Lo que se manifiesta a menudo en la identificación del judío como "agente" extraño dentro del corpus del país, retornando a la acusación popular de la "doble lealtad" nacional del judío, lanzada por los nacionalistas argentinos (Mirelman 1988: 55).

Las representaciones narrativas que se analizarán a continuación prestan de esta compleja realidad comunitaria y nacional sus argumentos al discutir los mitos y las realidades concernientes a lo judeoargentino y al símbolo de la tierra de promisión como tropo universal, que pueda ser anclado en varios entornos políticos, inclusive en Argentina e Israel. Es importante destacar que ambos países en sus iniciales etapas constituidoras postularon recibir a la nueva mano de obra migratoria como motor de cambio social; ambos países utilizaron el modelo del crisol de razas como vehículo de integración y aculturación de los recién llegados, y en ambos contextos nacionales, los anhelos de los inmigrantes remitieron al motivo bíblico al iniciar la nueva vida en la tierra que los recibió. Cuando nos toca analizar las representaciones narrativas del motivo de la tierra de promisión, deberíamos pensar si aún hoy el escritor judío oriundo de Israel es el único para quien la identidad judía no postula ab initio una relación adversaria con su Estado, particularmente si consideramos la acusación de la "doble" lealtad (Sosnowski 1987: 22). Históricamente, para muchos de los escritores judíos no israelíes, Israel supuestamente se percibió como el único espacio posible para reconciliarse, en donde los distintos rasgos

2 Aunque nunca se encontraron a los responsables de estos actos de terror, varias pistas indicaban los lazos con la organización de Jizbalah, y los países de Irán, Líbano y Siria (Lanata/Goldmann 1994). 
personales y comunitarios dependientes de cuestiones religiosas, nacionales y patrióticas se complementaban el uno con el otro sin resultar en una crisis personal o en un conflicto interno. Sin embargo, cabe evaluar la relevancia de esta postura en los últimos años. Israel, visto como la encarnación moderna del mito bíblico -objeto de deseo- y como segunda patria simbólica, ¿mantiene su predominio como el único espacio de reconciliación posible? No es mi deseo exponer aquí los argumentos respecto al papel de Israel como destino migratorio y el role del Otro en esa sociedad. Es suficiente decir que tanto Israel como Argentina, elegidos para comenzar una nueva vida, son espacios conflictivos en los que los procesos de aculturación e integración social se suman a otras dificultades existenciales. La alienación de los inmigrantes que arribaron a Israel en olas masivas durante la década de los cincuenta del siglo pasado, por ejemplo, particularmente los judíos de origen norafricano o los provenientes de países árabes, que fueron considerados menos "civilizados" por los judíos asquenazíes que entonces dominaban las instituciones oficiales del joven país, ya fue documentada en numerosos trabajos y obras de ficción. ${ }^{3}$ El proceso de aculturación de los inmigrantes mizrahim ("orientales", término referido hacia los inmigrantes del Medio Oriente) tuvo que ver con el abandono de ciertos ritos tradicionales, el cambio de apellidos y nombres y el aprendizaje forzado del hebreo (obligatorio para todos los inmigrantes al país) como clave para ser parte integral de la sociedad israelí. En otras palabras, la pérdida de ciertos elementos identitarios era necesaria para considerarse y ser considerados como "verdaderos" israelíes.

Al tener en cuenta esos paralelismos, conviene indagar respecto al caso judeoargentino cuáles fueron los cambios que ha generado la

3 En los años ochenta y noventa del siglo xx emergen en la literatura israelí nuevas voces narrativas que relatan la experiencia del Otro dentro de la sociedad israelí. Antón Shamas y Sayed Kashua, escritores palestinos y ciudadanos israelíes, escriben en hebreo sobre su propia historia en el país judío; Sami Michael y Dan Benaya-Seri relatan sus experiencias como inmigrantes judíos oriundos de países árabes; Dov Elbaum y Mira Magen escriben sobre otra minoría -la comunidad religiosa ultra-ortodoxa de Israel; la autora Dorit Rabinian, de origen judeo-iraní, quien representa la nueva generación de escritores israelíes, enmascara mediante anécdotas folclóricas en su narrativa el dolor y las dificultades de la integración en la sociedad sionista desde los años cincuenta hasta la era actual. 
revisión de los archivos colectivos, y qué representa la imagen de Sión dentro de esas nuevas perspectivas. ¿Cuáles son los nuevos significados que adquiere el motivo de la tierra de promisión dentro de la narrativa judeoargentina producida en los últimos años en Argentina y fuera de sus fronteras geográficas? ¿Corresponde hablar en términos de "marginalidad", "exclusión" y "dualidad" (términos asociados hasta hace muy poco con el ser judío) cuando exploramos el espectro de definiciones individuales y colectivas que han surgido en los últimos años? Mi planteamiento es observar la diversidad de significados que adquiere Sión como tema dentro de la obra literaria y ofrecer una perspectiva más crítica de esa noción, desnudándola de ese esplendor mitológico, y observándola al comparar la historia judeoargentina narrada desde Argentina e Israel.

La primera novela que deseo enfocar en este marco es La logia del umbral (2001) de Ricardo Feierstein, texto que expone la saga de la familia Schvel, inmigrantes judíos rusos que llegaron a Argentina a principios del siglo XX a la colonia de Moises Ville. La novela usa la imagen del umbral (en ídish "schvel") como metáfora de la existencia judía en Argentina y del sentimiento de dualidad al vivir "entre dos patrias": el país de los sueños, la Argentina deseada como un nuevo Sión, y el país de la realidad actual, la Argentina del post-atentado contra el edificio de la AMIA, a partir del 18 de julio de 1994. Al comenzar con el shock y la confusión inmediatamente después de la explosión, el texto propone revisar la supuesta integración social de los inmigrantes judíos mediante una serie de flashbacks a distintos momentos de la vida familiar, abriendo con el testimonio de Mariano Schvel, el miembro más joven del clan, relatado en primera persona:

Un ruido gigantesco, una obscena ráfaga de viento que me desprende de la montura y revolea por el aire. Todo se vuelve negro, el rugido ensordecedor parece indicar que, con la oscuridad de un eclipse gigante, ha llegado el fin de mundo (Feierstein 2001: 14).

De este modo, se destaca desde el principio de la obra la destrucción del mito fundador que vio el país como una nueva tierra de promisión. $\mathrm{El}$ acto terrorista abre el cuestionamiento en torno al lugar que ocupa la colectividad judía y sus miembros dentro del archivo argentino, al regresar a la imagen idílica presentada en la novela de Alberto Gerchunoff, Los gauchos judios (1910). La crítica hacia esa visión inocente y ficticia que no responde más a la realidad concreta, caracteri- 
zada por la violencia y el odio, el terror y los fracasos, examina la imagen de Sión de distintos modos. Ante todo, es una metáfora que no se consigna a cierto territorio geográfico o político; en cambio, representa el país deseado por los recién llegados para realizar un futuro posible, viendo en Argentina la nueva encarnación del mito bíblico.

Pero Sión es también un espacio factible concretizado en el territorio del Estado de Israel. Salomón Schvel, el hermano mayor, por ejemplo, quien emigró a Israel durante la dictadura, descubre con el pasar del tiempo que Argentina ya no es el objeto de su identificación personal y colectiva, sino Israel, su nuevo país de residencia. De su país de origen se conservan las costumbres, el idioma y los recuerdos, pero el presente y futuro giran alrededor de la calurosa ciudad de Be'er Sheva, donde reside. A la vez, Manuel, su primo, mantiene el lazo sentimental con el entorno argentino y sostiene su fe en el "crisol de razas" y en el símbolo gerchunoffiano del gaucho judío. Así, prefiere asumir su condición de minoría para quedarse en la zona limítrofe y enunciar desde ahí su papel como alguien que también "hizo la Argentina".

Al delinear el mapa retrasado por los caminos de la logia familiar, se evidencia el carácter ficticio y simbólico de esa figura como la representación de la colectividad judía en la Argentina. La logia, que jamás ha existido, excepto en el imaginario colectivo argentino y en la memoria y conciencia judías, se descubre como un artefacto que juega un papel dominante en la historia judía. Para los miembros de la familia, implica una posibilidad de elegir pertenecer a un espacio y conservar los valores y tradiciones; para la sociedad que los rodea, significa una distinción, una separación, un destino representado por la imagen del umbral. Ese artefacto, compuesto por memorias, tradiciones y mitos, carece de significado fuera del archivo colectivo y solamente prevalece como una metáfora de la experiencia judía en el país.

La obra cuestiona el plan integral representado por el calidoscopio lingüístico del habla de los personajes:

Quiero todo, lo argentino y lo judío, el mate y el samovar, el poncho y el talit, el Martín Fierro y el Talmud, porque soy todo, la mezcla y la superación de la mezcla, el andamio y la casa construida gracias a estos andamios que, ahora, debo retirar, para habitar la vivienda-identidad que he construido (Feierstein 2001: 245). 
¿Pero es realmente posible integrar dos patrias: la de residencia -Argentina- y la simbólica -Sión-, o se trata de optar por una de ellas? De acuerdo al texto, el dilema consiste en dos objetos de identificación que ocupan el mismo sitio: la patria concreta de la vivencia argentina y la patria soñada de la existencia judía. Según La logia, el conflicto puede resolverse de tres formas: al emigrar a otra parte, al encerrarse en un "gueto" o al asimilarse. Los que optan por la inmigración a Israel perciben la oportunidad de ser parte de una mayoría al convertirse en ciudadanos israelíes. Desenmascarada de su esplendor idílico, Argentina es reemplazada por Israel, que ofrece otro tipo de mestizaje: nuevos y viejos inmigrantes de África del Norte, Europa y el Medio Oriente, residentes nativos de la ciudad y del kibutz interactúan en ese espacio de la agrupación de las diásporas. Los que prefieren encerrarse dentro del "gueto" ven en Sión un objeto de deseo, siempre distante e inalcanzable, un símbolo nutrido por las raíces bíblicas. Por último, están los asimilados, que no buscan más encontrar sentido en este motivo. Israel, para ellos, forma parte de un pasado perdido e historia olvidada, que surgen de repente en momentos horrorosos como después del atentado, y que les recuerdan su residencia en el umbral. Ya que a pesar de ser abandonada por el judío asimilado, Sión representa todavía un lugar de rivalidad para los que lo rodean, identificándolo como un miembro culpable de esa indeseable "logia".

En la novela El árbol de la gitana (1997) de Alicia Dujovne Ortiz, la revisión de los mitos fundadores de la argentinidad y del judaísmo encuentra su propósito final en la tierra calurosa del Mar Muerto. Para la protagonista, cuya identidad homónima -Alicia Dujovne Ortizpropone introducir una historia autobiográfica, la decisión de partir al exilio en París en 1977, cuando la Junta militar asume el poder, desencadena la construcción del árbol de los relatos sobre previas experiencias errantes vividas e inventadas de su familia. El destierro en París provoca el deseo de recurrir a la serie de éxodos y aventuras de sus parientes viajeros, para intentar comprender, a través del despliegue de la trayectoria familiar, la razón de su marginalidad. El exilio desencadena una historia sin fin relatada por la protagonista/Sheherezade, perseguida por los fantasmas de sus ancestros y obsesionada por el pasado. Éste emerge a partir de las historias de la gitana, "gorda de papada blandita, vivo retrato de la demente anciana que seré" (Dujovne Ortiz 1997: 22), un álter ego híbrido de la narradora y de la fi- 
gura de su madre. Sus cuentos, que terminan siempre con una moraleja relevante a la situación actual de la protagonista, arman poco a poco el árbol genealógico y el rompecabezas que resulta ser la historia familiar. Asimismo, la repetición de la experiencia de los antepasados católicos y judíos a lo largo de los siglos se ofrece como una explicación del presente. Ese pasado, dominado por partidas y retornos, adquiere otra dimensión al sugerir que la condición errante es hereditaria y perpetua.

Todos buscan un patrimonio perdido en el texto de Dujovne Ortiz; la imagen de la tierra de promisión, en este sentido, representa ante todo el deseo de pertenecer y ser parte de un colectivo. Asimismo, abre la posibilidad de revisar los archivos para buscar la raíz flotante de la existencia individual y el origen perdido de las ramas judías y católicas de su familia. La primera visita a Israel ocurre durante la redemocratización en Argentina, y permite a la protagonista compartir con otros el dolor de la extranjería y el exilio, real e imaginario, sentidos hasta entonces. Tocar la tierra caliente del desierto favorece a la reformulación de los elementos de la identidad personal, mientras que el viaje a Israel, en donde se atan los fragmentos del pasado, simboliza para la protagonista una actitud actual deseada: tanto el cruce de las fronteras lingüísticas como el de las estatales resulta un gesto necesario para dialogar con una historia y para articular el destierro como otro artefacto en la construcción de la identidad contemporánea.

En el Mar Muerto sucede el último encuentro con los fantasmas del pasado, cuando la protagonista auto-cuestiona su modo de vivir: "y al final de esta historia, ¿qué soy yo sino cascotes y escombros sueltos?" (Dujovne Ortiz 1997: 292). La recolección de los fragmentos del pasado, por lo tanto, tarea realizada desde Israel y Francia, consiste en pensar en posibles "puntos de fuga" que llevarán desde el doloroso pasado hacia otro destino desconocido y que enseñarán cómo sobrevivir en un presente ambiguo. De esta forma, los elementos mesiánicos cabalísticos como, por ejemplo, la aceptación del exilio como una "misión" para reunir "las chispas dispersas por el mundo" (Dujovne Ortiz 1997: 293), se transforman en un medio para imaginar el hogar virtual deseado como espacio factible, construido poco a poco mediante la nostalgia: un lugar que tal vez no pueda existir, no haya existido y, sin embargo, se lo desea como el hogar verdadero. Tanto la Nueva York de sus amigos exiliados como la Jerusalén del congreso 
de escritores judíos o Bogotá -ciudad de residencia de su propia hijale dejan comunicar con otros su sentimiento de desubicación y el sueño con otras vidas posibles. Asimismo, la revisión de los archivos fundadores desde Israel permite expresar de otra manera la argentinidad y el sentido de ser judío al integrar lo fantástico y lo real, lo político y lo privado en un solo hilo narrativo, mientras que se mezclan las raíces y se abren caminos para recrear la historia personal y nacional.

Para el irónico protagonista de Marcelo Birmajer en Los tres mosqueteros (2001) -el periodista Mossen-, Sión, el judaísmo y la argentinidad se resumen de la siguiente manera:

A los treinta y dos años, mi judaísmo se había congelado en un imperecedero amor por el moderno Estado de Israel. Eso era todo lo que me quedaba luego de treinta años de vagar por el desierto de la duda (Birmajer 2001: 10).

Birmajer, cuya generación fue marcada por las experiencias de la democracia, la fragmentación y la cultura masiva global, opta por narrar desde un nuevo prisma. Mientras que la generación de Feierstein y Dujovne Ortiz expresa el dilema de la "doble" identidad y de la marginalidad como una experiencia personal vivida por los propios autores, Birmajer inventa este dilema en su texto, basándose en historias familiares, para reivindicar su identidad, dada por sentado desde el principio.

Esa nueva perspectiva que opta por la riqueza y el pluralismo abundantes en la identidad judeoargentina, ofrece un judaísmo más laico y menos tradicional. La pertenencia nacional del narrador no está cuestionada y se relaciona con otros motivos de identificación, más universales. Sión, en este sentido, forma parte integral de esta afiliación. La novela, que intenta recuperar la historia ausente de tres amigos judíos, los tres "mosqueteiros" (nombrados así por el barrio judío), comienza con el retorno a Argentina del único sobreviviente de los tres, Traúm, quien escapó a Israel durante los años de la dictadura después de su militancia con los montoneros, y quien desea encontrar un cierre mediante la nostalgia. Por su parte, Mossen, enviado a entrevistarlo, debe enfrentar sus propios fantasmas del pasado cuando se narra la historia de los tres amigos:

-Jugábamos... -dijo con la voz entrecortada-. Jugábamos [...]. Tratábamos de comportarnos como creíamos que se comportaban los no judíos. Alguna vez hicimos chistes antisemitas. Hablábamos de la circuncisión 
como si no estuviéramos circuncidados. Nos condolíamos de cómo debía dolerles ese chiste a los pobres paisanos. Nos agarrábamos la entrepierna y dejábamos escapar falsos suspiros de dolor por entre los dientes. Hablábamos de autos y de caballos [...]. Ser goy era una categoría única y definida, como lo es ser judío para muchos goy. Decíamos que nos casaríamos con Moria Casán, y que llamaríamos a nuestros hijos Antonio, Jesús y María. Nos congratulábamos de ser la mayoría religiosa del país. Éramos goy. En esa esquina (Birmajer 2001: 88-90).

No obstante y a pesar del tono nostálgico, este texto no propone más que narrar una pequeña historia de amor y de amistad sin ninguna crisis personal existente, como exponen las novelas analizadas previamente. Nada de exilios dolorosos y desterritorialización repetida, nada de vacilación y dudas eternas. Con su tono irónico y humorístico y al estilo periodístico, el narrador transforma el contexto histórico en una anécdota personal. Esta actitud deliberada por parte del texto se interpreta aquí como la carencia de un verdadero conflicto interno.

En este sentido, el sionismo, Israel, el hebreo o el ídish, junto con los recuerdos del pasado migratorio, se relacionan con una nueva sensibilidad multicultural, puesto que forman parte inherente e indiscutible del modo de ser. Esta nueva tendencia genera un tipo de judaísmo cool, laico y libre del peso de la historia y de la responsabilidad de la memoria colectiva, que permite "flotar" entre varias orillas -Israel, Argentina, la realidad virtual y la imaginación- sin tener que desembarcarse jamás bajo el amparo instantáneo y fugaz, como una nueva y legítima forma de expresarse.

Curiosamente, el tema de Argentina como la nueva tierra de promisión aparece en dos novelas publicadas en Israel, que retoman la historia judeoargentina para cuestionar esa noción. Mozart lo hayá yehudi ("Mozart no era judío", 1992), escrita por la autora argentinoisraelí Gabriela Avigur-Rotem, plantea reconstruir el árbol genealógico mediante las anécdotas de las familias Gurman y Gidekel, que inmigraron a Argentina a fines del siglo XIX. El texto expone la saga de las dos familias judías devenidas de Rusia en hebreo mezclándolo con expresiones en ídish, ruso y español y destacando así el mélange lingüístico acompañado por el sentimiento de alienación en el nuevo lugar de residencia. El estilo poético usado por la narradora distingue al hebreo del resto de los idiomas hablados como una lengua bíblica arcaica mediante una serie de expresiones simbólicas y líricas, características del texto sagrado, para reconstruir de este modo el crisol 
idiomático y cultural de los recién llegados. Sión se convierte aquí en un lugar concreto donde los sueños y la realidad se unen para ofrecer, por primera vez en la historia, una posibilidad de eliminar la distancia que separa entre lo narrado y lo vivido personalmente (una distancia a menudo ignorada por versiones canónicas y oficiales de pasado). Ser judío y ser argentino en este nuevo destino consiste en una nueva identidad: ser israelí; un inmigrante judío residente de un país dominado por judíos, cuyo futuro radica en la tierra bíblica, mientras que sus raíces se dispersan por el mundo.

Caracterizado por la desorganización cronológica y diegética, el texto manipula los elementos fantásticos al sugerir que tanto el destino como la destinación final se determinan por el azar. El efecto vacilante dentro de la novela es provocado cada vez que el texto se detiene sobre los motivos personales de cada personaje o las relaciones íntimas no declaradas abiertamente dentro del texto. Este efecto se relaciona asimismo con la ruptura espacial y temporal del hilo narrativo. RafaelAlberto Gidekel, por ejemplo, el hijo de Ida y León, destinado a casarse con Graciela Gurman, es capaz de mover objetos con su mirada y puede predecir el futuro; capacidad que responde, de cierta medida, a los intentos por parte de la narradora omnisciente de aludir al futuro mientras se relata el pasado:

Cuando le presioné para que admitiera que se ha olvidado completamente de esta profecía durante los años que han pasado desde entonces, me dijo: "es cierto, no sabes lo difícil que es recordar lo que fue y lo que será, sin mezclarlos a ambos". Entonces, según su opinión, "puede ser que yo haya encontrado la hipoteca, sólo que aún no lo sé, por eso te pregunté tantas veces sobre la cadena e intenté también sacar algo de él, de algún modo, pero sabes cómo es después de lo que pasó con Graciela”. Pero aún no.

Todavía están juntos para dar a luz a la cadena de hijas, que se envolverá opulentamente alrededor de los elásticos tobillos de Graciela, quien confundía la sed que constantemente atacaba su cuerpo después de los partos con la sed de un vacío, deseando rellenarse y germinar vida; todavía están juntos, riéndose a escondidas, a orillas del lago opaco de los secretos familiares (Avigur-Rotem 1992: 245, mi traducción, A. R.).

A diferencia de otras novelas, Mozart narra el pasado migratorio con otro propósito, permitiéndonos reexaminar los elementos biográficos e históricos concernientes a la experiencia migratoria y a la imagen de Sión como tierra de promisión. Cabe notar que en este texto la desterritorialización y el sentimiento diaspórico no se resuelven con el re- 
torno a la tierra bíblica soñada, es decir, con la emigración a Israel. El tono particular del texto consiste en la experiencia marginal compartida entre la narradora y los personajes. La posibilidad de reconciliarse al eliminar la distancia geográfica con el objeto de deseo -Sión-, como sugiere la narradora, es evidente cuando comprende como adulta que en este nuevo destino todos sufren de un tipo de dislocación interna debido a una experiencia errante milenaria. Recuperar el archivo implica aceptar esta situación como enriquecedora y como invitación que incita a crear. Aquí reside el interés por el pasado y la necesidad de recrear estos episodios como una alternativa plausible que reflejara las condiciones de aquel momento particular. Es también la razón por la cual la historia debe ser relatada en hebreo desde el origen recuperado, ya que es la lengua reclamada por los propios inmigrantes.

Según los Gurman y los Gidekel, la imagen idealizada de Sión que representa la patria original es asociada con un doble sentimiento de lealtad, puesto que desafía el lugar reclamado por la patria de residencia -Argentina-, exponiendo así la raíz del dilema personal. Sin embargo, este conflicto es relacionado con otra problemática generada en Israel por motivos similares que conducen a otro tipo de marginalidad. Avigur-Rotem enfatiza respecto a eso su identificación con el imaginario argentino inscrito en las minúsculas diferencias mentales y culturales de cada sociedad, que consiste en una distinción permanente (a pesar del tiempo transcurrido) en aquel "nivel de tono"; la condición de "vivir entre dos patrias" mencionada al principio de este trabajo. Por lo tanto, esa dualidad no se resuelve con la inmigración a Israel, sino es reemplazada por otro tipo de confrontación: en Argentina, el deseo es encontrar la tierra de promisión e imaginar al país como una Sión de "segunda mano", mientras que en Israel, en la tierra bíblica original, el verdadero hogar de la infancia es lamentado: la Argentina de la nostalgia infantil. Mozart ofrece al lector aceptar el episodio migratorio como una condición básica del ser judío. En este sentido, Israel y Argentina aparecen como espacios conflictivos donde procesos de aculturación e integración social se suman a otras dificultades cotidianas.

La novela utiliza el tema de la errancia para cuestionar el sueño del origen promisorio. Al clausurar el texto con el arribo de varios parientes a Israel y con la reconstrucción del árbol genealógico desde ahí, el texto retoma la noción de marginalidad para observar si en el 
nuevo lugar de residencia desaparece el sentimiento de extranjería. Sin embargo, según indica la novela, Sión no ofrece al final ninguna solución factible, sólo abre la posibilidad de narrar una historia que, por primera vez, parece coincidir con la versión oficial del Estado (es decir, Israel). La narradora crea una doble equivalencia entre el mito y la realidad en dos entornos distintos: en Argentina, los conflictos de "doble" identidad y alienación social predominan; en Israel, los sueños del retorno se chocan con las duras condiciones económicas y políticas del Estado judío. El crisol de razas, modelo deseado por ambas autoridades nacionales, pierde su importancia como modelo de integración y expone el mestizaje racial y étnico que domina finalmente cada una de esas sociedades. Por último, tanto el hebreo como el español, lenguas de origen penetradas por términos extranjeros, se exponen como signos de sociedades en medio de transformación.

También la novela Maase be-tabaat ("Una hazaña de anillo", 2007) de Ilan Sheinfeld relata la historia migratoria judía a Argentina y el mito de Sión. Este texto regresa a un episodio silenciado en la historia argentina -la trata de blancas en los burdeles de la Zwi Migdal- para recrear la historia de tres generaciones de mujeres judías. El texto comienza con Esperanza Gantz, quien revela un día a su hija un secreto familiar terrible sobre su verdadero origen como descendiente de prostitutas, quienes emigraron desde Danzig a Argentina con la esperanza de combatir el destino y la pobreza, sólo para desilusionarse y caer de nuevo en la trampa de la prostitución para sobrevivir. Relatado en primera persona, el texto manipula diferentes elementos derivados del misticismo judío y la fantasía para relatar la historia de un anillo misterioso fabricado para curar: un testigo mudo del azar y la raíz de conflictos y rivalidades. Saltando de Europa a Argentina, de Argentina a Israel y de vuelta a Buenos Aires, el texto sugiere revisitar la historia silenciada como un testimonio; un mapa del pasado olvidado y de la "melodía triste, la melodía de todo judío, hecha de lamentos por generaciones" (Sheinfeld 2007: 458).

Creado según fórmulas cabalísticas secretas para curar la epilepsia que corre en las venas de la aristocrática familia Bergman, el anillo es robado y termina cayendo en las manos de Lea, la abuela de Esperanza, una pobre prostituta de Danzig, que sufre de epilepsia también. La novela propone que el azar es más fuerte que cualquier deseo e intención humanos, ya que por miedo a que el destino vergonzoso se repi- 
tiera, Lea esconde el anillo mágico y decide enviar a su hija a Buenos Aires para salvarla de un futuro idéntico. Una vez en la capital porteña, la pobre joven inmigrante cae en las manos de los rufianes judíos y termina trabajando en los prostíbulos, continuando así la tradición infame. Es solamente natural suponer que Esperanza, nacida en una de esas casas notorias, cumpliera con ese destino también. Con el pasar del tiempo, es el turno de Esperanza de convertirse en madre y de temer por la suerte de su propia hija. Para evitar otra repetición de la historia, la protagonista decide enviar a su hija a un orfanato al imaginar otro futuro posible para la siguiente generación. No obstante, con la dictadura militar de 1976, Esperanza, desesperada por la seguridad de su hija, decide enviarla a Israel, como último rescate. Es ahí, en la tierra donde la memoria es pura y fresca, según afirma el narrador, que el anillo misterioso encuentra su propósito original de curar, y regresa a su dueño, la familia Bergman. En una cadena de eventos retorcidos, el texto propone ver en Israel un espacio de reconciliación y cambio, donde el pasado de prostitución se acaba con una historia de amor lesbiana entre la hija de Esperanza y Graciela Bergman, la heredera del anillo. El objeto mágico, por ende, se convierte en símbolo de su compromiso amoroso y afección, regalado a ellas por Esperanza como última ofrenda:

Hay relatos que comienzan bien y hay relatos que comienzan mal. Hay relatos satisfechos con poco, como en el pueblo de Shedletz, y hay relatos cuya hambre no conoce satisfacción [...]. Eso es lo que ocurrió a este relato, que comenzó en Shedletz y que terminó en la tierra de Israel, iniciando con un anillo. Pero en este anillo hay un tipo de magia que no puede existir acá, en Israel. Aquí hay otras magias. Es una tierra de magias pequeñas. La vida opresa, el calor nubla los sentidos. En este aire no crecen grandes milagros. Los demonios necesitan la gran oscuridad para crecerse. También aquí hay ciudades pobladas por demonios. Pero las ciudades de aquí son nuevas, y los demonios-importados por judíos que los hayan traído de sus lugares de origen (Sheinfeld 2007: 456).

Paradójicamente, a pesar del supuesto final alegre, el texto concluye que justamente ahí, en la tierra de Israel, la encarnación del mito de la tierra de promisión, el pasado es borrado de la memoria colectiva deliberadamente como un método de purificación que elimina las experiencias del dolor para conservar el núcleo del relato. La historia, en consecuencia, se ficcionaliza como estrategia de supervivencia en el territorio de Sión. 
Si los primeros textos que enfocaron el mito de la tierra de promisión lo relataron como una utopía, y Sión radicaba "allí donde reina la alegría y la paz", según señalaba Gerchunoff, con el logro sionista de regresar al origen, a la tierra bíblica, y con el establecimiento del Estado de Israel, Sión se convirtió en espacio tangible, un destino de emigración, mientras que Argentina reveló su cara como un país alienante con la desilusión de las últimas décadas. Junto con las propuestas de Marcelo Birmajer y de Alicia Dujovne Ortiz, que dejan de ver en la duda y en la vacilación metáforas deseables de la condición judeoargentina, se destacan la marginalidad y el sentimiento diaspórico como el resultado de la experiencia errante, perpetua e inherente, que caracteriza al inmigrante judío desde principios del tiempo, percibida también en la propia Sión. A veces, según indica la novela de Sheinfeld, la reconciliación requiere quebrar con las normas familiares, morales y religiosas para poder pensar en puntos de fuga.

El motivo de la tierra de promisión siempre remitió a dos espacios paralelos: a la patria virtual inscripta en el mito de origen, y a un lugar concreto que presentaba nuevas oportunidades para los que deseaban partir. Es el retrato de Sión como espacio abierto para el cambio y la transformación el que ofrece un plano virtual para desembarcarse. En este sentido, Argentina puede ser percibida como otro punto fugaz en el largo éxodo judío hacia el destino final; otros la ven como el umbral entre el pasado y el futuro, la realidad y la imaginación. Otro espacio de silencios y dudas, donde el azar y el destino se cruzan y reúnen como si fuera el propio texto. Mientras que la vacilación y el cuestionamiento, expresados en la novela de Feierstein, enfatizan nociones conocidas como el sentimiento diaspórico y marginal, el texto de Dujovne Ortiz usa la destrucción de los mitos fundadores y la aceptación de la errancia para expresar otro modo de ser. Jerusalén, como Buenos Aires, París o Bogotá, son meramente espacios temporales para reflexionar. Asimismo, para Birmajer, el meditar en el pasado se convierte en expresión de una nostalgia readymade, artefacto que sirve al propósito de la narración, ya que no consiste en dilemas personales referentes a la pertenencia y lealtad nacionales. La tierra de promisión no se concretiza en el texto de Birmajer ni en la Argentina actual ni en el Estado de Israel, y menos en algún territorio político en especial. Como lo demuestran también las novelas de Sheinfeld y AvigurRotem, el texto narrativo parte y retorna a la memoria como estrategia 
literaria para luchar contra el olvido, el verdadero desafío en el nuevo contexto fragmentado y vacilante.

¿Podríamos localizar la tierra de promisión en algún sitio dentro de este mapa de relatos e historias? Tal vez no como un lugar concreto, real o imaginario, sino como una variedad de posibilidades desafiantes, intrigantes y confusas, un rizoma que suma y multiplica incesantemente los diversos significados de lo judeoargentino. Esa multiplicidad de representaciones, más que indicar una clausura o conclusión, marca vectores para escapar de lo obvio y narrar lo oculto. Tal vez en este acto se halle su verdadera promesa.

\section{Bibliografía}

Avigur-Rotem, Gabriela (1992): Mozart lo hayá yehudí. Jerusalem: Keter.

Birmajer, Marcelo (2001): Tres mosqueteros. Madrid: Debate.

Chab, Silvia (2001): Entre la crisis y la esperanza: la comunidad judeoargentina tras el atentado a la AMIA. Buenos Aires: Catálogos.

Dujovne Ortiz, Alicia (1997): El árbol de la gitana. Buenos Aires: Aguilar.

Feierstein, Ricardo (2001): La logia del umbral. Buenos Aires: Galerna.

Gerchunoff, Alberto ([1910] 1997): Los gauchos judios. Tel Aviv: Lewin-Epstein Ltd.

Lanata, Jorge/Goldman, Joe (1994): Cortinas de humo: una investigación independiente sobre los atentados contra la embajada de Israel y la AMIA. Buenos Aires: Planeta.

Mirelman, Victor (1988): En búsqueda de una identidad: los inmigrantes judios en Buenos Aires 1890-1930. Buenos Aires: Milá.

Sheinfeld, Ilan (2007): A Tale of a Ring [Maase be-tabaat]. Jerusalem: Keter.

Sosnowski, Saúl (1987): La orilla inminente: escritores judios argentinos. Buenos Aires: Legasa. 
